Article

\title{
The Antioxidant and Anti-Aging Effects of Acetylated Mycelia Polysaccharides from Pleurotus djamor
}

\author{
Huaping Li ${ }^{1,2}$, Huajie Zhao ${ }^{2}$, Zheng Gao ${ }^{2}$, Xinling Song ${ }^{2}$, Wenshuai Wang ${ }^{2}$, Fangfang Yuan ${ }^{2}$, \\ Yanbo Feng ${ }^{2}$, Yiwen Zhang ${ }^{2}$, Jianjun Zhang ${ }^{2}$, Shuliang Zhang ${ }^{1, *}$ and Le Jia ${ }^{2, *(D)}$ \\ 1 Dezhou Academy of Agricultural Sciences, Dezhou 253015, China \\ 2 College of Life Science, Shandong Agricultural University, Taian 271018, China \\ * Correspondence: dzzhshl@126.com (S.Z.); jiale0525@163.com (L.J.); Tel.: +86-053-8824-9958
}

Academic Editor: Isabel C.F.R. Ferreira

Received: 3 June 2019; Accepted: 14 July 2019; Published: 24 July 2019

\begin{abstract}
The present work mainly describes the preparation of acetylated mycelia polysaccharides (AMPS) from Pleurotus djamor and investigates the antioxidant and anti-aging effects in D-galactose-induced aging mice. The optimized procedure indicates the acetyl substitution degree of AMPS is $0.54 \pm 0.04$ under the conditions of a reaction time of $56 \mathrm{~h}$, a reaction temperature of $37^{\circ} \mathrm{C}$, and $4 \mathrm{~mL}$ of added acetic anhydride. The in vitro analysis and in vivo animal experiments indicate that the AMPS could alleviate the aging properties by scavenging the radicals, elevating the enzyme activities, and reducing the lipid contents. As for serum levels, the AMPS can improve the serum biochemical indices and enhance immunological activity. The histopathological observations indicate that the injuries to the liver, kidney, and brain can be remitted by AMPS intervention. The characterization showed that AMPS was one kind of $\beta$-pyranose with the weight-average molecular weights of $3.61 \times 10^{5} \mathrm{Da}$ and the major monosaccharides of mannose and glucose. The results suggest that AMPS can be used as a dietary supplement and functional food for the prevention of aging and age-related diseases.
\end{abstract}

Keywords: acetylated mycelia polysaccharides; Pleurotus djamor; antioxidant effects; anti-aging effects

\section{Introduction}

It has been reported that aging, as an inevitable and physiological process which can induce the gradual loss of body function and increase the probability of age-related diseases, including diabetes, cognition impairment, cancer, liver damage, Parkinson's disease, and atherosclerosis, has become a considerable challenge in health and life ability [1-3]. D-galactose (D-gal) can react with free amines of amino acids as a physiological reducing sugar and further form mashing terminal products. Mammals that are exposed long-term to excess D-gal can fall victim to induced accelerated aging, including regression of the hematopoietic system and bone marrow [4]. Oxidation is essential for many organisms in all biological processes related to energy metabolism. However, excess free radicals can be scavenged by antioxidants, which interact with free radicals against oxidative stress [5]. Oxidative stress can be generated by producing reactive oxygen species (ROS) in the application process of D-gal.

However, the long-term use of chemically synthesized antioxidants can be toxic and carcinogenic, so it is important to find effective alternative natural antioxidants. Edible and medicinal mushrooms are rich in polysaccharides, balanced nutrients, dietary fiber, and other compounds which are physiologically beneficial to humans [6]. It was proven that polysaccharides from mushrooms play significant roles in refraining from oxidative damage in living organisms as inartificial free radical scavengers and have better effects than synthetic antioxidants [7]. Published studies have demonstrated that polysaccharides are abundant and can be isolated, purified, and structurally characterized and possess biological functions, such as anti-tumor, hepatoprotective, anti-inflammatory, anti-viral, 
antioxidative, and anti-microbial activities [8,9]. Pleurotus djamor, which is classified in the genus Pleurotus of the family Pleurotaceae, has been authenticated as an edible and medicinal mushroom and verified to have disease-resistance and health protective effects. Moreover, polysaccharides from $P$. djamor have been affirmed to possess multiple biological activities, including antioxidant, antitumor, and immune adjustment activities in many certified research examples [10]. Additionally, the purification, characterization, and hepatoprotective activities of mycelia zinc polysaccharides by P. djamor were studied by Zhang et al. [11], but acetylation modification of P. djamor has not been researched before. Acetylation is an important modification method for polysaccharides' branched chains and the activity of polysaccharides is closely related to the structure, molecular weight, and solubility of polysaccharides [12]. An acetyl group can change the extension of polysaccharides, lead to the exposure of a polysaccharides hydroxyl group, increase the solubility of polysaccharides in water, improve the physiological activity of polysaccharides, and make polysaccharides be used effectively [13]. Furthermore, previous literature found that acetylated modification polysaccharides can significantly improve their cytoprotective and antioxidant activities, including resisting reactive oxygen [14].

From the above, polysaccharides can serve as age-defying, momentous, natural edibles that can assist chemical medicines. However, there are few studies that pay close attention to the anti-aging function of the acetylated mycelia polysaccharides (AMPS) of P. djamor, so it is necessary to explore this. The present experiment was aimed to describe the antioxidant activity in vitro, anti-aging activities in vivo, and evaluate the effects of AMPS on D-gal induced-aging mice.

\section{Results}

\subsection{AMPS Acetyl Substitution Degree}

Results of single-factor and response surface optimization experiment are shown in Figure 1. The predicted value of substitution degree (DS) can be calculated by the following formula: DS $=0.54+$ $0.02 \times \mathrm{A}-7.5 \times 10^{-3} \times \mathrm{B}-0.015 \times \mathrm{C}+0.01 \times \mathrm{A} \times \mathrm{B}+0.01 \times \mathrm{A} \times \mathrm{C}-0.015 \times \mathrm{B} \times \mathrm{C}-0.025 \times \mathrm{A}^{2}-0.085 \times$ $B^{2}-0.03 \times C^{2}$. The optimal conditions for acetyl substitution were determined as a reaction time of $56 \mathrm{~h}$, a reaction temperature of $37^{\circ} \mathrm{C}$, and $4 \mathrm{~mL}$ of added acetic anhydride (Supplementary Files S1).

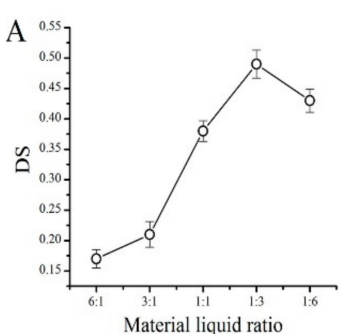

E

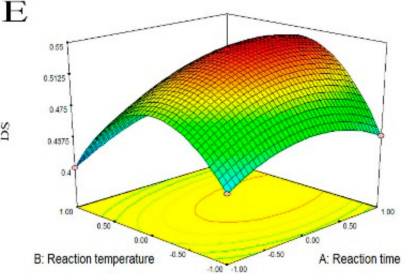

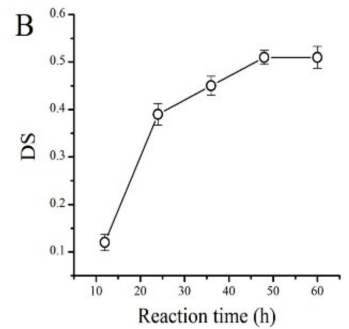

$\mathrm{F}$

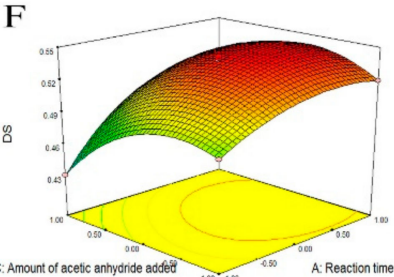

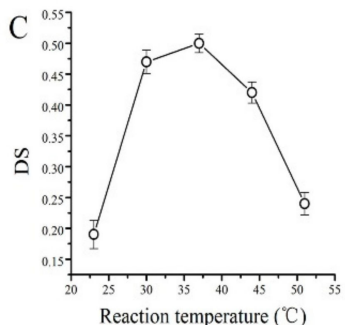

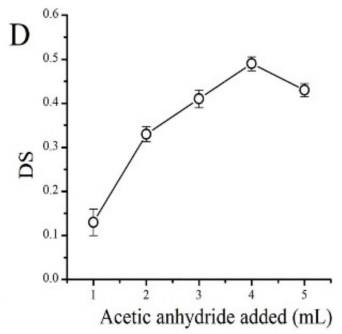

G

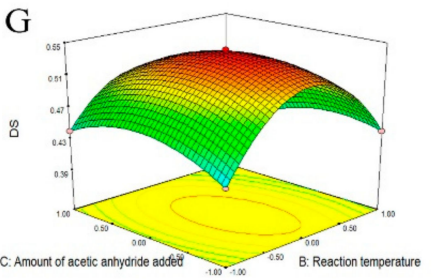

Figure 1. Results of single-factor and response surface optimization experiment. Influences of (A) material ratio, (B) reaction time, $(\mathbf{C})$ reaction temperature, and (D) the amount of acetic anhydride added to DS in single-factor test. Influences of $(\mathbf{E})$ reaction time and reaction temperature, $(\mathbf{F})$ reaction 
time and the amount of acetic anhydride added, and (G) reaction temperature and the amount of acetic anhydride added to DS in the response surface optimization experiment. Factors that were not included in the axes were fixed at their respective optimum levels. The values were reported as the means $\pm \mathrm{SD}$ ( $n=10$ for each group). Means with the same letter had no significant difference $(p<0.05)$.

DS: substitution degree.

The absorbance at $500 \mathrm{~nm}$ was $0.38 \pm 0.03$ and the concentration of solution in the $50 \mathrm{~mL}$ volumetric flask was $0.025 \pm 0.003 \mathrm{mg} / \mathrm{mL}$ with the acetyl standard curve (Figure 2). The w2 value was $12.50 \pm$ 0.18 according to the formula and the DS value was $0.54 \pm 0.04$.

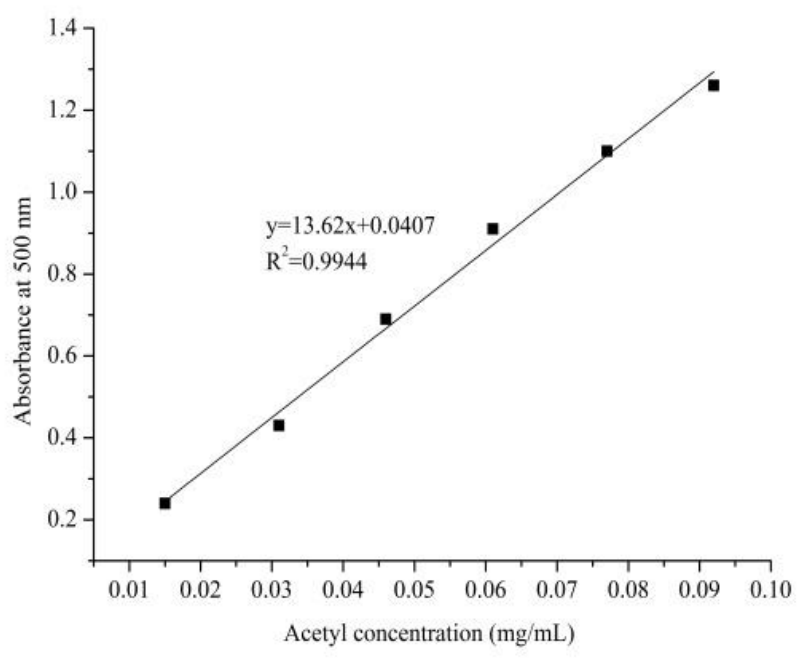

Figure 2. Standard curve of acetyl content.

\subsection{FT-IR, HPLC, and NMR Analysis}

The FT-IR spectrum of AMPS is presented in Figure 3A. A strong and broad absorption peak at $3700-3100 \mathrm{~cm}^{-1}$ for $-\mathrm{OH}$ vibrations, two peaks for $\mathrm{C}-\mathrm{H}$ within the range of $3000-2800 \mathrm{~cm}^{-1}$, and several compact absorption peaks in the region of $1200-1000 \mathrm{~cm}^{-1}$ for $\mathrm{C}-\mathrm{OH}$ and the $\mathrm{C}-\mathrm{O}-\mathrm{C}$ glycosidic band vibrations existed for AMPS. All these characteristic absorptions indicated that the FT-IR spectrum belonged to the acetylated mycelia polysaccharides from P. djamor. Additionally, the figure showed a doughty absorption between $1655 \mathrm{~cm}^{-1}$ and $1550 \mathrm{~cm}^{-1}\left(1577.37 \mathrm{~cm}^{-1}\right.$, accurately) and was typical of $\mathrm{N}$-acetylglucosamine residues. We ascertained the successful acetylation and the remarkable substitution effect of AMPS through this extremely obvious absorption peak $[15,16]$. There was also a symmetrical, strong, stretching vibration carboxyl peak at $1410.39 \mathrm{~cm}^{-1}$. The absorption peaks at $1000-700 \mathrm{~cm}^{-1}$ were characteristic peaks formed by $\alpha$-pyranose and $\beta$-pyranose and the absorption peaks near the $890 \mathrm{~cm}^{-1}$ band $\left(880.17 \mathrm{~cm}^{-1}\right.$ in the FT-IR spectrum) were characteristic peaks formed by the $-\mathrm{CH}$ bending vibration of $\beta$-pyranose, meaning that the AMPS was a kind of $\beta$-pyranose [17]. 


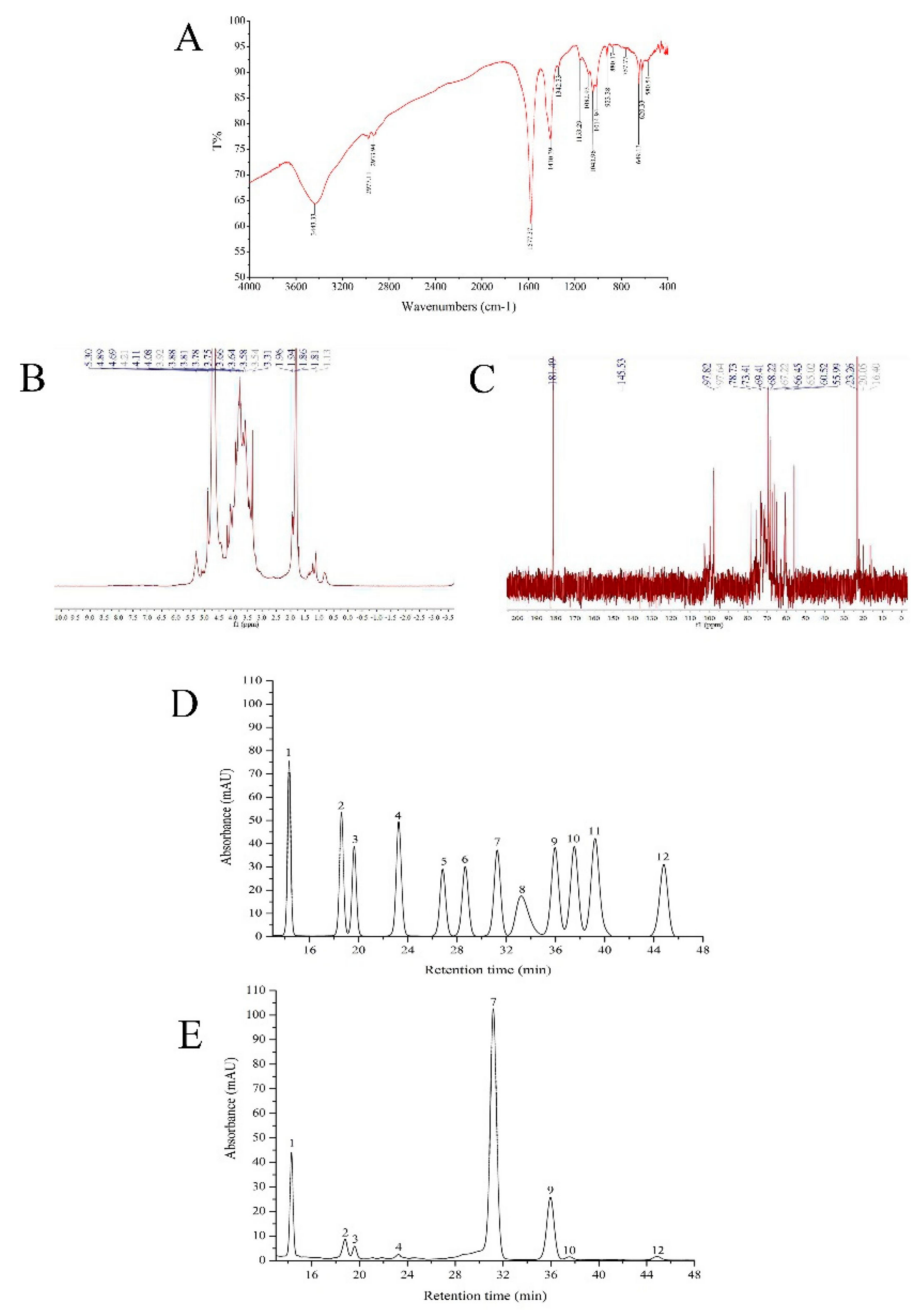

Figure 3. Physicochemical analysis of acetylated mycelia polysaccharides (AMPS). (A) FT-IR spectra over the range of $400-4000 \mathrm{~cm}^{-1}$, (B) NMR analysis of ${ }^{1} \mathrm{H}$ spectra and (C) ${ }^{13} \mathrm{C}$ spectra, and (D) gas chromatography of 12 standard monosaccharides. Peaks: (1) Mannose, (2) ribose, (3) rhamnose, (4) glucuronic acid, (5) galacturonic acid, (6) glucosamine, (7) glucose, (8) galactose, (9) galactose, (10) xylose, (11) arabinose, and (12) fucose. (E) Gas chromatography of AMPS.

The HPLC chromatogram indicated that AMPS was a heterogeneous polysaccharide. The Mw (weight-average molecular weight), Mn (number-average molecular weight), and Mz (mean grain size) of the AMPS were $3.61 \times 10^{5} \mathrm{Da}, 2.06 \times 10^{5} \mathrm{Da}$, and $6.85 \times 10^{5} \mathrm{Da}$, respectively. The ratio value of $\mathrm{Mz} / \mathrm{Mw}$ was 1.90 .

The ${ }^{1} \mathrm{H}-\mathrm{NMR}$ spectrum of AMPS (Figure 3B) represented the peak of $\mathrm{D}_{2} \mathrm{O}$ at $4.69 \mathrm{ppm}$; two fairly strong signals of anomeric protons at 4.89 and 5.30 ppm were observed, possibly indicating that the AMPS was mainly composed of two types of monosaccharides. The ${ }^{1} \mathrm{H}-\mathrm{NMR}$ spectrum also showed the set of wide and intense signals between 3.0 and $4.0 \mathrm{ppm}$, which manifested in $\mathrm{CH}_{2}-\mathrm{O}$ and $\mathrm{CH}-\mathrm{O}$ groups present in AMPS. Moreover, the anomeric regions of 0.9-2.0 ppm and 3.2-5.5 ppm were the general representative carbohydrate peaks. The signal of $\mathrm{D}_{2} \mathrm{O}$ in the ${ }^{13} \mathrm{C}-\mathrm{NMR}$ spectrum (Figure $3 \mathrm{C}$ ) was at 181.49 ppm and the AMPS potentially contained at least two monosaccharides due to the anomeric carbon signals at 97.64 and $97.82 \mathrm{ppm}$, which agreed with the ${ }^{1} \mathrm{H}-\mathrm{NMR}$ spectrum analysis. Other important signals in the present spectra were those in the area of 60-80 ppm, where they were related to $C_{2}, C_{3}, C_{4}, C_{5}$, and $C_{6}$ from the glycosidic ring. In addition, the absence of $\alpha$-anomeric configurations in AMPS could be reflected because there were no signals during 98-102 ppm. The wide and intense peaks at 60-110 ppm suggested the presence of $\beta-(1 \rightarrow 3)$ glucans in AMPS [11,18]. 
Comparing the retention time of the standards (Figure 3D), the AMPS was composed of mannose, ribose, rhamnose, glucuronic acid, glucose, galactose, xylose, and fucose in a percentage composition of $12.51 \%, 3.96 \%, 2.0 \%, 0.99 \%, 60.49 \%, 18.02 \%, 0.92 \%$, and $1.10 \%$ (Figure 3E). Mannose and glucose among the above eight kinds of monosaccharides may be the two types of monosaccharides in the ${ }^{1} \mathrm{H}-\mathrm{NMR}$ spectrum; the monosaccharide composition of AMPS was ascertained by HPLC.

\subsection{Antioxidant Properties In Vitro}

In this experiment, to determine the antioxidant activities of the AMPS in vitro, reducing power analysis, scavenging 1,1-diphenyl-2-picrylhydrazyl (DPPH) radical assay, and scavenging assays on hydroxyl and superoxide radicals were conducted and the results are presented in Figure 4. The reducing power of AMPS was increased with the increase of sample concentrations (Figure 4A). At a concentration of $1000 \mathrm{mg} / \mathrm{L}$, the absorbance at $700 \mathrm{~nm}$ reached $0.47 \pm 0.02$ and the $50 \%$ effective concentration $\left(E_{50}\right)$ level was $620 \mathrm{mg} / \mathrm{L}$. It can be seen from Figure $4 \mathrm{~B}$ that the scavenging DPPH radical role increased with the increasing concentrations of the polysaccharides. At a concentration of 1000 $\mathrm{mg} / \mathrm{L}$, the scavenging DPPH radical effect was $64.09 \pm 1.34 \%$ and the $50 \%$ inhibitory concentration $\left(\mathrm{IC}_{50}\right)$ level was $580 \mathrm{mg} / \mathrm{L}$. The scavenging hydroxyl radical abilities with concentrations ranging from 100 to $1000 \mathrm{mg} / \mathrm{L}$ were depicted in Figure 4C. The results indicated that AMPS had a potential scavenging result with a concentration-dependent manner. The scavenging hydroxyl radical value reached $28.91 \%$ $\pm 1.24 \%$ under a concentration of $1000 \mathrm{mg} / \mathrm{L}$ and the $\mathrm{IC}_{50}$ level was $715 \mathrm{mg} / \mathrm{L}$. The dose-response curve for scavenging superoxide radicals activities of AMPS are shown in Figure 4D. The scavenging rate reached $55.05 \% \pm 1.96 \%$ at $1000 \mathrm{mg} / \mathrm{L}$ and the $\mathrm{IC}_{50}$ level was $585 \mathrm{mg} / \mathrm{L}$.
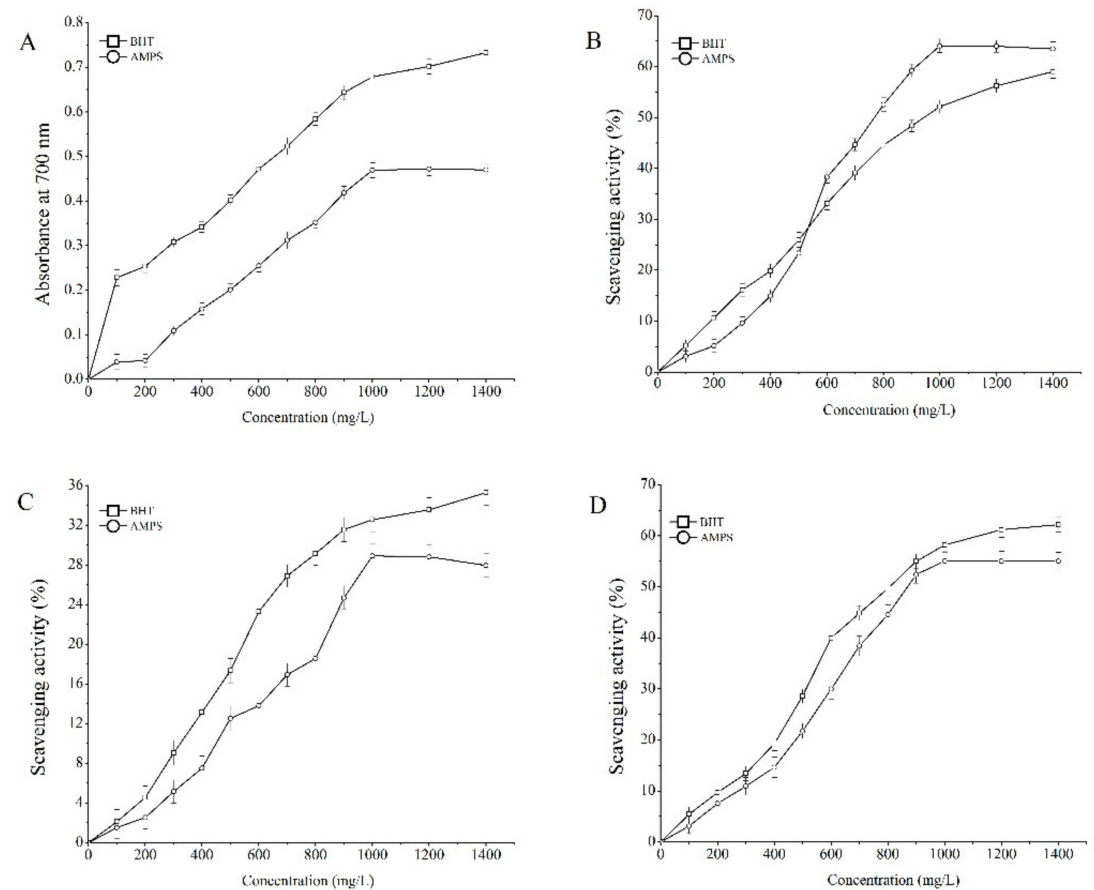

Figure 4. Antioxidant activities of AMPS in vitro. (A) Reducing power, (B) scavenging ability on 1,1-diphenyl-2-picrylhydrazyl (DPPH) radicals, (C) scavenging ability on hydroxyl radicals, and (D) scavenging ability on superoxide anion radicals. The values were reported as means $\pm \mathrm{SD}(n=10$ for each group). Means with the same letter had no significant difference $(p<0.05)$.

\subsection{Oral Chronic Toxicity Studies}

Obviously, no significant changes of behavioral, autonomic, or toxic responses, as well as no deaths, were observed in the mice treated with AMPS, even at doses of $900 \mathrm{mg} / \mathrm{kg} / \mathrm{d}$, not only at the end of the experiment, but also during the investigation period. 


\subsection{Effects of AMPS on Body Weight, Liver, and Kidney Indexes}

The effects of AMPS on body weight, liver, and kidney indexes in aging mice induced by D-gal are displayed in Table 1. At the onset of the experiments, there was no significant difference $(p<0.05)$ between the body weights of model control (MC) and the other groups. However, at the end of the experiment, the aging mice in the $\mathrm{MC}$ group exhibited a significant loss of weight when compared to the mice in the normal control (NC) group $(p<0.05)$. When compared with the mice in the MC group, the mice in the two dose groups exhibited significant improvement in the loss of body weight after the administration of the polysaccharides. Additionally, the results indicated that high dosage group (H-AMPS) showed a stronger effect on improving body weight, which was very close to the values in the positive control (PC) group. After administering AMPS at a high dose of $400 \mathrm{mg} / \mathrm{kg} / \mathrm{d}$, the weights increased by $18.31 \% \pm 0.09 \%$ compared with the MC group $(p<0.05)$ and the weights at a low dose of $200 \mathrm{mg} / \mathrm{kg} / \mathrm{d}$ increased by $12.62 \% \pm 0.08 \%(p<0.05)$.

Table 1. Effects of AMPS on body weight, liver, and kidney indexes in D-gal-induced aging mice.

\begin{tabular}{cccccc}
\hline \multirow{2}{*}{ Groups } & \multicolumn{2}{c}{ Body Weight $\mathbf{( g )}$} & $\begin{array}{c}\text { Liver Index } \\
(\mathbf{g} / \mathbf{1 0 0 g})\end{array}$ & $\begin{array}{c}\text { Kidney Index } \\
(\mathbf{g} / \mathbf{1 0 0 g})\end{array}$ & $\begin{array}{c}\text { Brain Index } \\
(\mathbf{g} / \mathbf{1 0 0 g})\end{array}$ \\
\cline { 2 - 4 } & Initial & Final & & & \\
\hline NC & $24.72 \pm 1.21$ & $41.44 \pm 1.28$ & $7.54 \pm 0.21$ & $3.78 \pm 0.05$ & $1.05 \pm 0.05$ \\
MC & $25.11 \pm 0.97$ & $32.89 \pm 1.44^{\mathrm{a}}$ & $13.38 \pm 0.19^{\mathrm{d}}$ & $6.33 \pm 0.09^{\mathrm{e}}$ & $3.79 \pm 0.12$ \\
$\mathrm{PC}$ & $24.98 \pm 1.12$ & $39.63 \pm 1.57^{\mathrm{bc}}$ & $8.26 \pm 0.14^{\mathrm{b}}$ & $3.94 \pm 0.04^{\mathrm{b}}$ & $1.12 \pm 0.06$ \\
$\mathrm{AMPS}$ & & & & & \\
$400 \mathrm{mg} / \mathrm{kg} / \mathrm{d}$ & $25.02 \pm 1.45$ & $38.91 \pm 1.31^{\mathrm{bc}}$ & $8.96 \pm 0.22^{\mathrm{b}}$ & $4.25 \pm 0.04^{\mathrm{c}}$ & $1.56 \pm 0.04$ \\
$200 \mathrm{mg} / \mathrm{kg} / \mathrm{d}$ & $24.35 \pm 1.34$ & $37.04 \pm 1.19^{\mathrm{b}}$ & $9.21 \pm 0.18^{\mathrm{c}}$ & $4.98 \pm 0.06^{\mathrm{d}}$ & $2.11 \pm 0.09$ \\
\hline
\end{tabular}

The values were reported as means $\pm \mathrm{SD}$ ( $n=10$ for each group). Means with the same letter had no significant difference $(p<0.05)$. NC: normal control, MC: model control, and PC: positive control.

Furthermore, the liver, kidney, and brain indexes in the mice were also investigated and are expressed as liver, kidney, or brain weight/body weight (g/100 g) in Table 1 . There were significant augmentations in the liver index and kidney index that could be observed in the aging mice of the MC group when compared to the NC group $(p<0.05)$, indicating that liver and kidney damage occurred after six weeks post-D-gal injection. Moreover, the liver and kidney indexes were found to decrease after the treatment with AMPS at two dosages. In the H-AMPS group, the liver and kidney indexes were severely reduced by $33.03 \% \pm 0.16 \%$ and $32.86 \% \pm 0.56 \%$, which were higher than the changes observed in low dosage group (L-AMPS) $(31.17 \% \pm 0.05 \%$ and $21.33 \% \pm 0.33$, respectively), indicating that both dosages of AMPS had certain protective effects against the D-gal-induced liver and kidney injury. However, there were no significant differences $(p>0.05)$ in brain index. A possible reason for this is that the quality of the brain was relatively light and therefore could not accurately reflect the brain damage caused by D-gal-induced aging and the alleviating effect of polysaccharides in terms of brain index. Therefore, the subsequent ELISA method was used to detect the nerve growth factor (NGF), tumor necrosis factor- $\alpha$ (TNF- $\alpha$ ), and B-lymphoma factor-2 (Bcl-2) in the serum, which largely reflected the influence of aging on brain tissue (Figure 6).

\subsection{Anti-Aging Properties In Vivo}

\subsubsection{Effects of AMPS on SOD, GSH-Px, and CAT Activities}

When compared to the normal control group, mice in the model control group showed some abnormal behavior characteristics, such as slow reactions, reduced feeding, and sparse hair. The death ratio was also higher, suggesting the success of aging model construction in the behavioral aspects of aging mice. The mice in the dose groups, which were given $400 \mathrm{mg} / \mathrm{kg} / \mathrm{d}$ and $200 \mathrm{mg} / \mathrm{kg} / \mathrm{d}$ respectively, showed better manners when compared with those in the MC group. So the reliability of the following 
experimental samples can be ensured, further studies on the anti-aging properties in vivo should be carried out [19].

The results of the superoxide dismutase (SOD), glutathione peroxidase (GSH-Px), and catalase (CAT) activities in the liver, kidney, and brain are distinctly exhibited in Figure 5. The SOD, GSH-Px, and CAT activities of the mice in the MC group decreased dramatically all in livers, kidneys, and brains when compared with the NC group. After six weeks of intraperitoneal injection administration, the GSH-Px activities in the livers, kidneys, and brains of H-AMPS (200.38 $\pm 4.37 \mathrm{U} / \mathrm{mg}$ prot (U/mg protein) in the liver, $121.45 \pm 2.09 \mathrm{U} / \mathrm{mg}$ prot in the kidney, and $56.98 \pm 1.22 \mathrm{U} / \mathrm{mg}$ prot in the brain) increased significantly $(p<0.05)$ compared with those of the model control group $(56.12 \pm 1.05 \mathrm{U} / \mathrm{mg}$ prot in the liver, $42.33 \pm 1.89 \mathrm{U} / \mathrm{mg}$ prot in the kidney, and $21.19 \pm 1.54 \mathrm{U} / \mathrm{mg}$ prot in the brain) (Figure $5 \mathrm{~A}-\mathrm{C}$ ). The SOD activities of the livers, kidneys, and brains in the H-AMPS group $(124.37 \pm 2.09 \mathrm{U} / \mathrm{mg}$ prot in the liver, $73.55 \pm 2.01 \mathrm{U} / \mathrm{mg}$ prot in the kidney, and $54.96 \pm 0.49 \mathrm{U} / \mathrm{mg}$ prot in the brain) increased significantly $(p<0.05)$ compared with those of the model control group $(81.54 \pm 1.56 \mathrm{U} / \mathrm{mg}$ prot in the liver, $52.14 \pm 1.23 \mathrm{U} / \mathrm{mg}$ prot in the kidney, and $39.35 \pm 0.86 \mathrm{U} / \mathrm{mg}$ prot in the brain). The administration of AMPS significantly $(p<0.05)$ enhanced SOD activities in a dose-dependent manner, especially in the H-AMPS group. For example, the SOD activities in the brain were increased by $39.67 \% \pm 0.43 \%$ compared with the MC group, which was higher than that of the positive control group $(35.93 \% \pm$ $0.17 \%$ ) (Figure 5D-F). The CAT activities in the liver, kidney, and brain reached $135.32 \pm 2.43 \mathrm{U} / \mathrm{mg}$ prot, $180.75 \pm 4.86 \mathrm{U} / \mathrm{mg}$ prot, and $179.18 \pm 2.71 \mathrm{U} / \mathrm{mg}$ prot, respectively, following treatment with AMPS at a dosage of $400 \mathrm{mg} / \mathrm{kg} / \mathrm{d}$. These values were significantly higher than those observed in the MC and increased by $3.13 \% \pm 0.48 \%$ in the kidney and $6.36 \% \pm 0.03 \%$ in the brain compared with the positive group (Figure $5 \mathrm{G}-\mathrm{I}$ ).
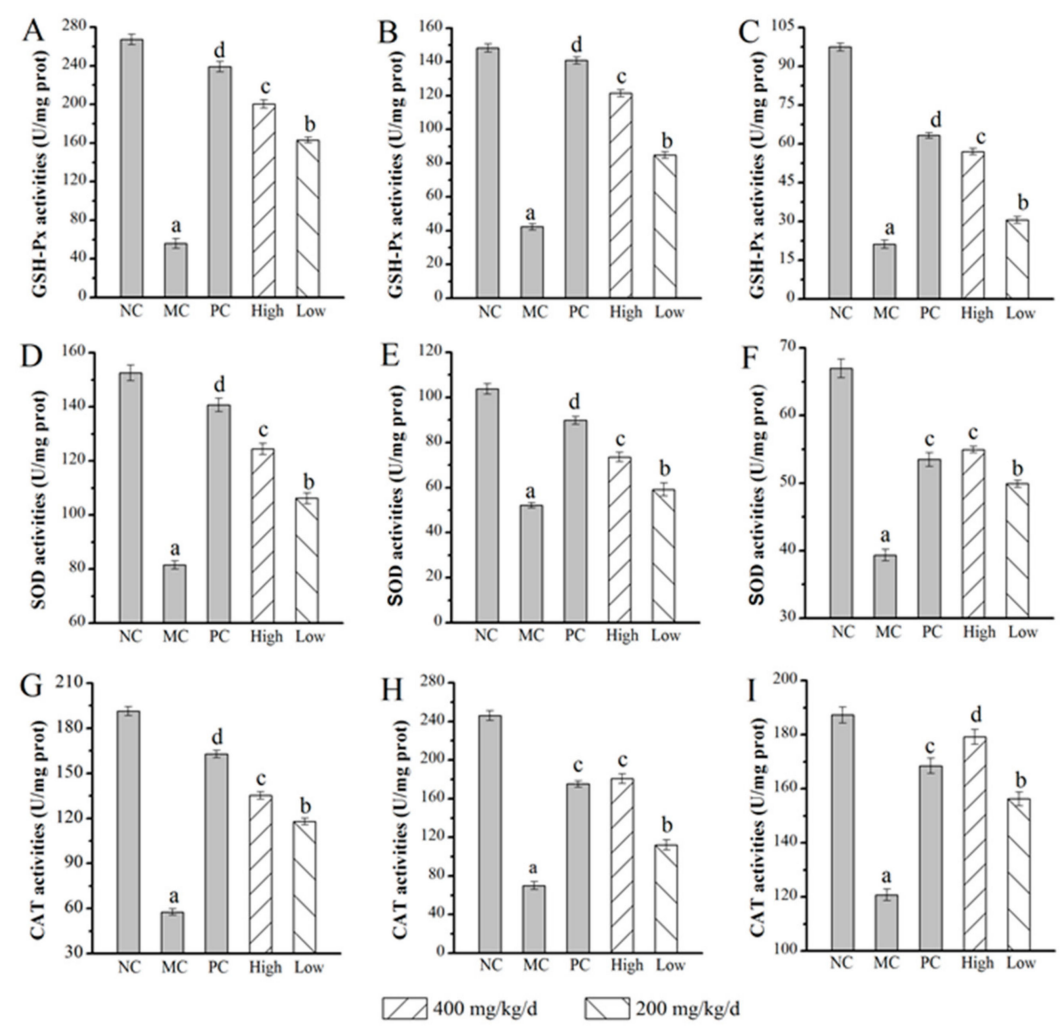

Figure 5. Effects of AMPS on the activities in liver of GSH-Px (A), SOD (D), and CAT (G), in kidney of GSH-Px (B), SOD (E), and CAT (H), and in brain of GSH-Px (C), SOD (F), and CAT (I), respectively. The values were reported as means $\pm \mathrm{SD}$ ( $n=10$ for each group). Means with the same letter had no significant difference $(p<0.05)$. SOD: superoxide dismutase, GSH-Px: glutathione peroxidase, and CAT: catalase. 


\subsubsection{Effects of AMPS on MDA and LPO Contents}

A significant increase in malondialdehyde (MDA) and lipid peroxide (LPO) contents (Table 2) was observed in the model control group compared with the normal control group. The MDA contents of H-AMPS and L-AMPS in the liver were reduced by $56.85 \% \pm 0.57 \%$ and $29.22 \% \pm 0.24 \%$ with dose-dependent patterns at the test concentrations compared with the MC group, respectively. There were also significant decreases in MDA levels observed both in the kidney $(61.09 \% \pm 0.57 \%)$ and in the brain $(33.40 \% \pm 0.16 \%)$ after the polysaccharide intragastric administration as compared to the MC group, indicating that AMPS could relieve the aging of mice undergoing D-gal treatment. Similarly, the LPO contents in both dose groups were also lower than those in MC group, especially for the H-AMPS group $(42.6 \% \pm 0.46 \%$ of liver, $47.78 \% \pm 0.43 \%$ of kidney, and $42.47 \% \pm 0.41 \%$ of brain). The potential capacity of AMPS to relieve the injury in the liver, kidney, and brain was also presented by values of LPO with a dose-dependent tendency.

Table 2. Effects of AMPS on the MDA and LPO contents of the liver, kidney, and brain.

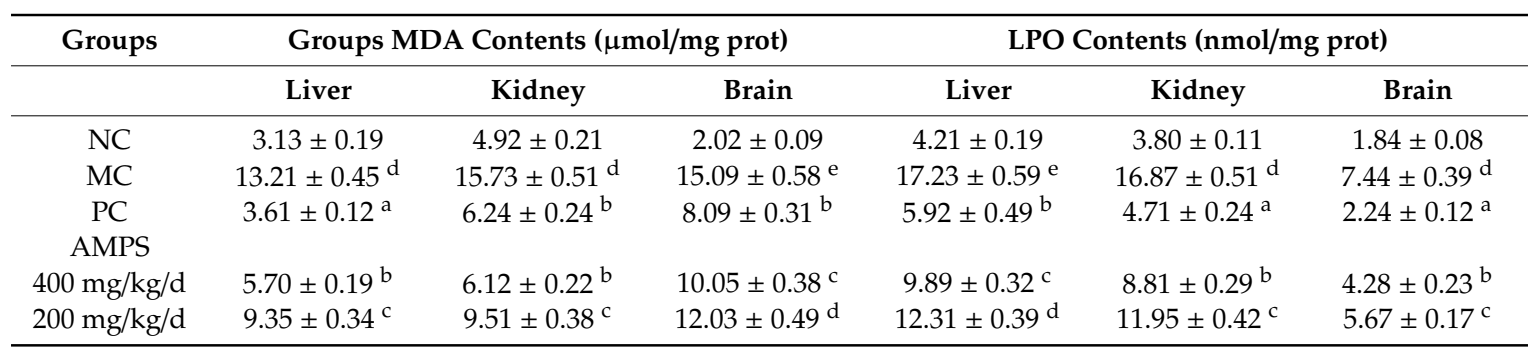

The values were reported as means \pm SD $(n=10$ for each group). Means with the same letter had no significant difference $(p<0.05)$. MDA: malondialdehyde, LPO: lipid peroxide and prot: protein, respectively.

\subsubsection{Effects of AMPS on the Serum Biochemical Index}

As shown in Figure 6, the mice in the MC group showed serious organic damage, which was evidenced by significant increase in the activities of alanine transaminase (ALT), cholinesterase (CHE), creatine kinase (CK), and aspartate aminotransferase (AST), as well as levels of total bilirubin (TBIL), creatinine (CREA), total cholesterol $(\mathrm{CHO})$, and glucose (GLU) (all with $p<0.05)$ when compared with those in the NC group. The TBIL and CHO levels and CK activities were $1.2 \pm 0.1 \mu \mathrm{mol} / \mathrm{L}, 2.7 \pm$ $0.2 \mathrm{mmol} / \mathrm{L}$, and $1123 \pm 53 \mathrm{U} / \mathrm{L}$ in mice treated with AMPS at a dosage of $400 \mathrm{mg} / \mathrm{kg} / \mathrm{d}$, which were significant lower than that in the MC group $(2.5 \pm 0.1 \mu \mathrm{mol} / \mathrm{L}, 3.7 \pm 0.1 \mathrm{mmol} / \mathrm{L}$, and $2183 \pm 113 \mathrm{U} / \mathrm{L}$, respectively, $p<0.05$ ) (Figure 6B,G,E). Furthermore, the GLU level in the H-AMPS group decreased by $47.81 \% \pm 0.19 \%$ compared with the MC group $(15.77 \pm 0.63 \mathrm{mmol} / \mathrm{L})$ (Figure $6 \mathrm{H})$. The AST and CHE activities (123 $\pm 3 \mathrm{U} / \mathrm{L}$ and $110 \pm 1 \mathrm{U} / \mathrm{L}$, respectively) of mice exerted $400 \mathrm{mg} / \mathrm{kg} / \mathrm{d}$ polysaccharides were significantly decreased (Figure 6C,F). ALT activities and CREA levels showed the H-AMPS group (42 $\pm 6 \mathrm{U} / \mathrm{L}$ and $63 \pm 2 \mu \mathrm{mol} / \mathrm{L}$, respectively) had superb effects on D-gal-induced aging mice when compared with the MC group $(p<0.05)$ (Figure 6A,D). 

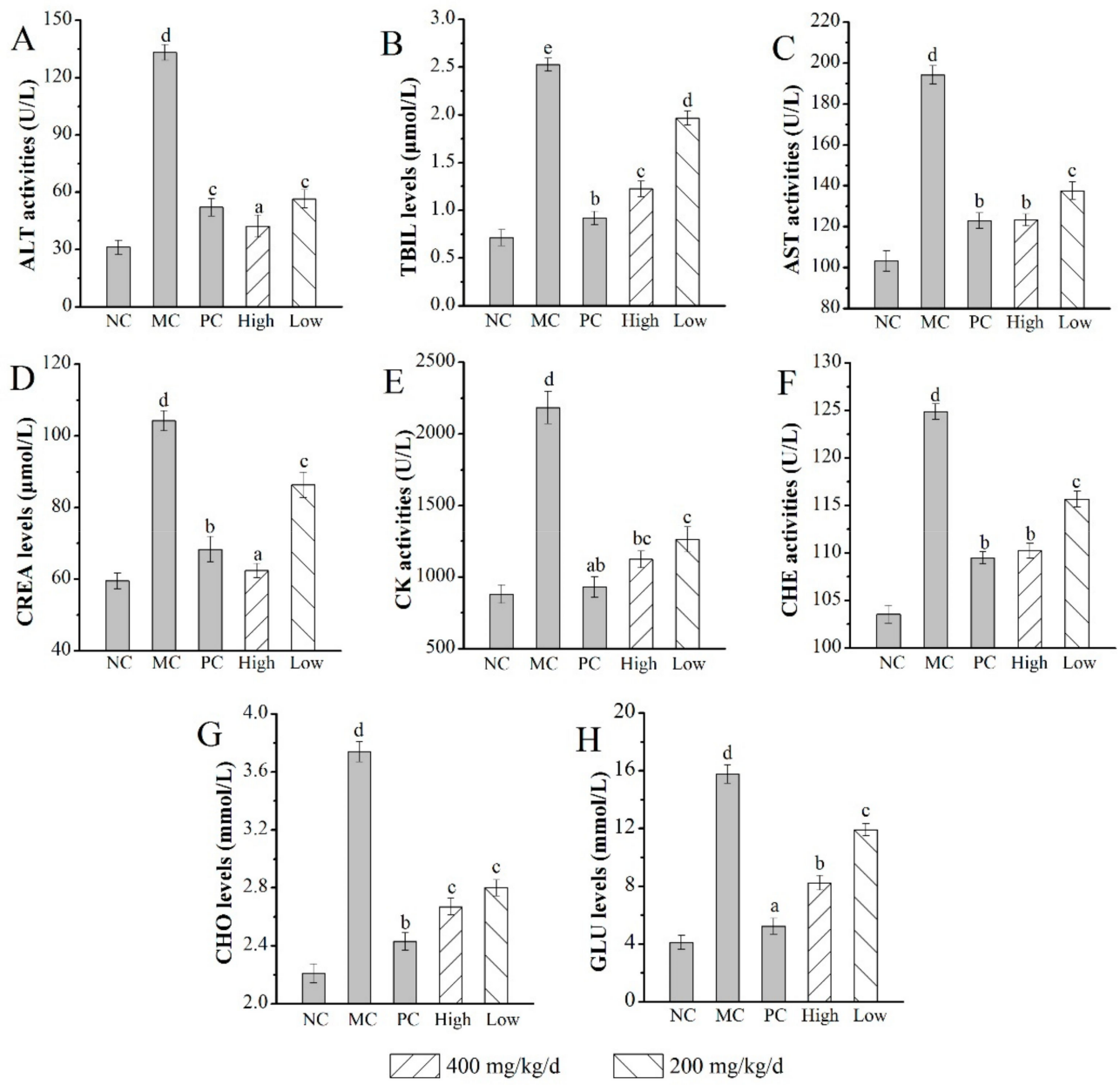

Figure 6. Effects of AMPS on (A) ALT activities, (B) TBIL levels, (C) AST activities, (D) CREA levels, (E) CK activities, (F) CHE activities, (G) CHO levels, and (H) GLU levels in D-gal-induced aging mice. The values were reported as means $\pm \operatorname{SD}(n=10$ for each group). Means with the same letter had no significant difference $(p<0.05)$. ALT: alanine transaminase, CHE: cholinesterase, CK: creatine kinase, AST: aspartate aminotransferase, TBIL: total bilirubin, CREA: creatinine, CHO: total cholesterol, and GLU: glucose.

In this experiment, the levels of inflammatory cytokines NGF, TNF- $\alpha$, and Bcl-2 in the serum were commonly used as biochemical markers for tissue damage. As shown in Figure 7, the levels of NGF and Bcl-2 in the MC group were evidently decreased when compared with those in the NC group $(p<0.05)$, while the value of TNF- $\alpha$ showed an obvious uptrend. The results illustrated that the inflammatory reaction appeared in various kinds of tissues, including liver, kidney, and brain. Interestingly, after the treatment with AMPS at a dosage of $400 \mathrm{mg} / \mathrm{kg} / \mathrm{d}$, NGF levels reached $112.121 \pm 7.01 \mathrm{pg} / \mathrm{mL}$ with an increasing rate of $313.14 \% \pm 0.29 \%$ (Figure 7A), TNF- $\alpha$ levels reached $123.362 \pm 4.00 \mathrm{ng} / \mathrm{L}$ decreased by $40.28 \% \pm 0.56 \%$ compared with the MC group (Figure 7B), and Bcl-2 levels reached up to $33.133 \pm 0.28 \mu \mathrm{g} / \mathrm{mL}$ with an increasing rate of $13.78 \% \pm 0.07 \%$ when compared with the MC group (Figure 7C), respectively. These results indicated that AMPS could regulate the expression of these cytokines commendably. 


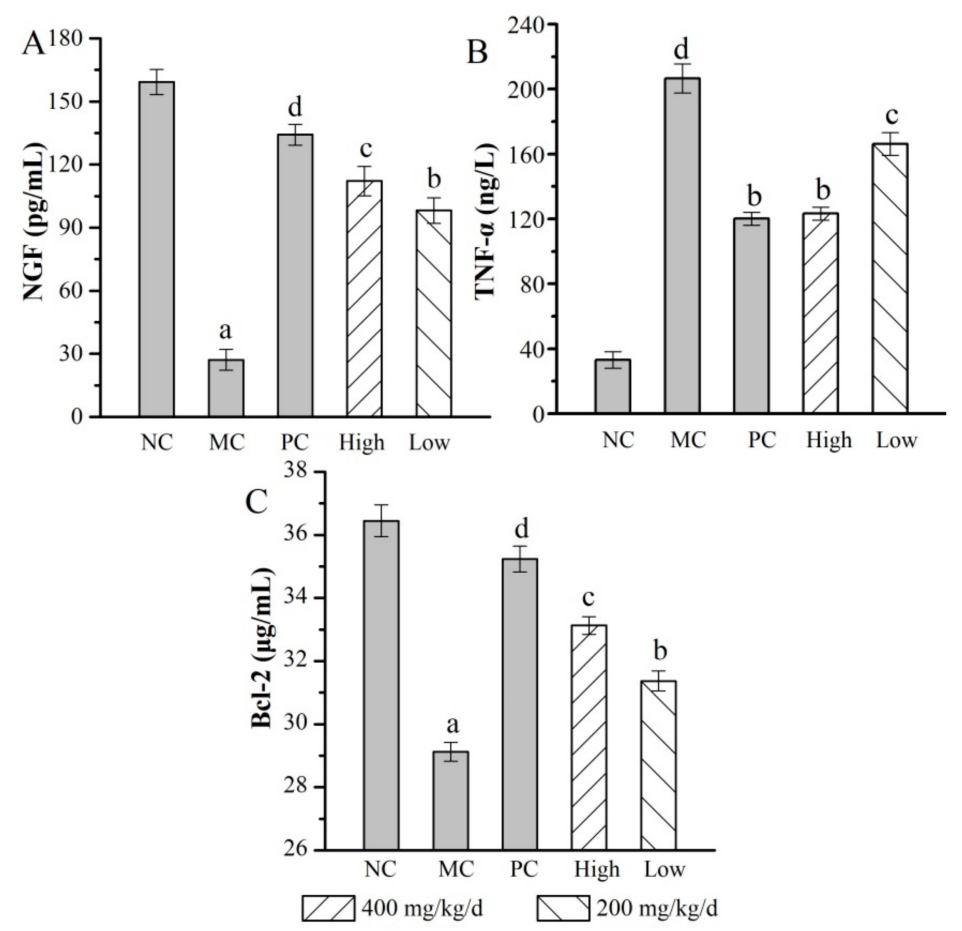

Figure 7. Effects of AMPS on the levels of (A) NGF, (B) TNF- $\alpha$, and (C) Bcl-2 in D-gal-induced aging mice. The values were reported as means $\pm \operatorname{SD}(n=10$ for each group). Means with the same letter had no significant difference $(p<0.05)$. NGF: nerve growth factor, TNF- $\alpha$ : tumor necrosis factor- $\alpha$, and Bcl-2: B-lymphoma factor-2.

\subsubsection{Histopathological Observations}

In the current work, histopathological observations of the liver, kidney, and brain samples were performed to corroborate the evidence from biochemical analyses (Figure 8). As shown in Figure 8A, when compared with the normal hepatic architectures of mice in the NC group with normal cell structures, large circular nuclei located in the center of the cell, rich cytoplasm, and clear cytomembranes, the liver sections of the MC group showed severe hepatocyte apoptosis, hepatocellular swelling, fatty accumulation, a loss of cellular boundaries, and other inflammatory changes. The histopathologic pathological injuries of mice fed with AMPS were ameliorated, according to a diminution of necrotic zones and color change, especially at the dose of $400 \mathrm{mg} / \mathrm{kg} / \mathrm{d}$. In a histopathological study of the kidney (Figure 8B), the tissue slice of the NC group exhibited glomeruli that were clear in structure, normal in size and shape, clear in structure and interstitial area of tubules. There was also no dilation of tubular lumen and no hyperplasia of fibrous tissue in the renal interstitium for the NC group, while the MC group showed irregular interstitial areas of the renal tubules, dilated lumens, inflammatory cell infiltration, and fibrous tissue proliferation. The mice in the dose groups of polysaccharides appeared to have less renal injury compared with the MC group. In the study of the effect of AMPS on the morphology of brain necrotic cells (Figure 8C), neurons in the hippocampal cortex of the NC group had intact morphology, with the nuclei and cytoplasm in the center, clear staining, and a large number and good arrangement of neurons. The necrotic cells in the MC group were disordered and the nerve fibers were loose and vacuolated. In particular, the number of vacuolar neurons in the H-AMPS group was significantly lower than that in the MC group, meaning that the degree of degeneration and necrosis of nerve cells in the polysaccharide group was decreased. 
A

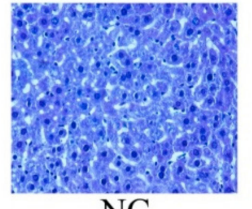

NC

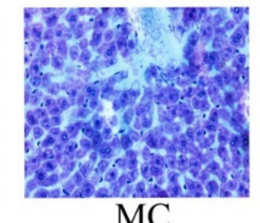

$\mathrm{MC}$

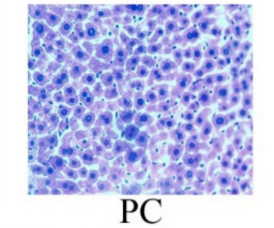

PC

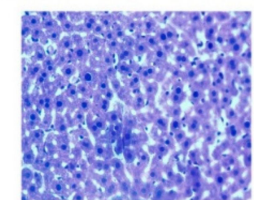

H-AMPS

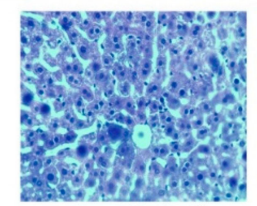

L-AMPS

B

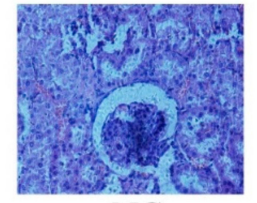

$\mathrm{NC}$

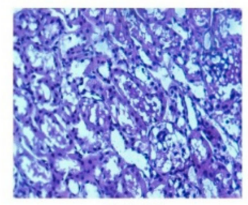

MC

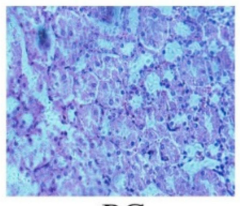

PC

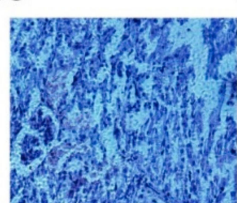

H-AMPS

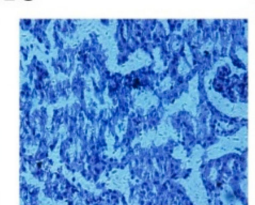

L-AMPS

C

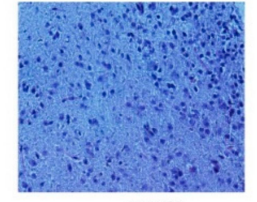

NC

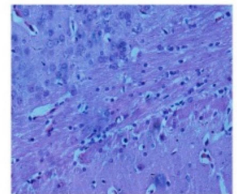

$\mathrm{MC}$

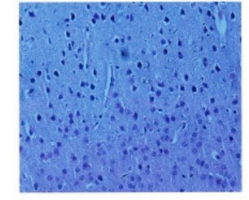

PC

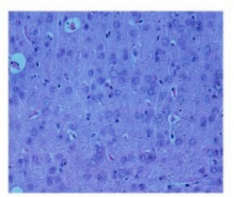

H-AMPS

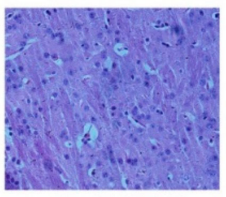

L-AMPS

Figure 8. Effects of AMPS on organ damage of (A) liver, (B) kidney, and (C) brain in D-gal-induced aging mice at the dosage of $400 \mathrm{mg} / \mathrm{kg} / \mathrm{d}$ (H-AMPS), showing slight architectural damage, and 200 $\mathrm{mg} / \mathrm{kg} / \mathrm{d}$ (L-AMPS), showing mild architectural damage (hematoxylin-eosin staining, magnification 400×).

\section{Discussion}

Aging patients are more likely to suffer from chronic diseases, including cancer, hypertension, atherosclerosis, idiopathic pulmonary fibrosis, osteoarthritis, Alzheimer's disease, Parkinson's disease, cataracts, and so on. Therefore, the aging mechanism and anti-aging have become more important in research. In this work, the D-gal-induced aging model was adopted. The mechanisms of this model include mitochondrial disorders, gene dysfunction, protein homeostasis imbalance, nutritional metabolic signal changes, stem cell injury, inflammatory aging, and oxidative stress, which was the mechanism studied in this paper [20,21]. Oxidative stress induces the destruction of molecular structures and redox signaling pathways that interfere with the oxidation-antioxidant balance [22]. An appropriate level of oxidative stress is critical for cell survival and homeostasis, but severe oxidative stress can lead to cell damage and death [23]. Edible and medicinal fungal polysaccharides have been studied for their various beneficial effects on the human body [24]. Natural polysaccharides are poly-hydroxyl compounds and nucleophilic substitution can occur on the active hydroxyl group under 
appropriate conditions, generating corresponding polysaccharide esters [25]. In recent years, many reports have involved the chemical modification of polysaccharides, including acetylation, which can improve the biological activity of polysaccharides through molecular modification [26]. In this experiment, only the relevant content of AMPS at a substitution degree of $0.54 \pm 0.04$ was carried out and the conditions for obtaining the optimal substitution degree of mycelium polysaccharides from Pleurotus ostreatus need to be further studied. It was shown that the weak dissociation energy of the $\mathrm{O}-\mathrm{H}$ bond caused hydrogen to be donated to a superoxide anion easily and the scavenging radical capacity was related to the amount of the $-\mathrm{OH}$ group $[27,28]$. The content of $\mathrm{C}=\mathrm{O}$ and $\mathrm{C}-\mathrm{O}$ bands rose because of the acetylation of mycelium polysaccharides (MPS) from P. ostreatus and the antioxidant activity increased with the change of polysaccharide elongation [13]. Data from present work indicated that the FT-IR spectrum of AMPS not only changed between $1655 \mathrm{~cm}^{-1}$ and $1550 \mathrm{~cm}^{-1}$, which was caused by acetylation, but two peaks were also added at $3000-2800 \mathrm{~cm}^{-1}$, expressing the $\mathrm{C}-\mathrm{H}$ of polysaccharides compared with mycelia zinc polysaccharides, reported by Zhang et al. [11]. The structure of AMPS was further explained from different angles by HPLC and NMR spectrum analysis, which was beneficial to study the structure-activity relationship of polysaccharides.

Moreover, the antioxidant activity of polysaccharides can be affected by the introduction of ion groups at appropriate levels [28]. The reducing power, as well as scavenging DPPH, hydroxyl, and superoxide radical activities, is widely used to investigate the antioxidant activity in vitro. Many literature pieces have reported that fungi polysaccharides have scavenging effects on these radicals, which can cause lipid peroxidation and further lead to various diseases [28-30]. Through this experiment, it was found that, when the substitution degree was $0.54 \pm 0.04$ in AMPS from P. djamor, the reducing power and the scavenging rates on the DPPH radicals, hydroxyl radicals, and superoxide anion radicals not only were increased in a dose-dependent way, but even had better antioxidant effects in vitro than mycelia zinc polysaccharides (MZPS), studied by Zhang et al. [12]. In this partial result, the antioxidant capacity in vitro of AMPS showed a more significant upward trend starting from the concentration of $500 \mathrm{mg} / \mathrm{L}$ to the last concentration gradients. The scavenging DPPH radical rate of polysaccharides even surpassed the dibutyl hydroxytoluene (BHT), an antioxidant reagent used as control group, beyond this concentration.

There is increasing evidence that oxidative stress can obstruct the major antioxidant enzyme systems by reducing the activities of glutathione peroxidase, superoxide dismutase, and catalase [31]. GSH-Px is a selenoenzyme that can directly react with ROS to prevent the formation of hydroxyl radicals induced by $\mathrm{H}_{2} \mathrm{O}_{2}$. SOD can convert superoxide anion radicals into $\mathrm{H}_{2} \mathrm{O}_{2}$ to form a defense system of antioxidant enzymes against reactive oxygen species, thus playing an anti-aging role. CAT can catalyze the metabolism of hydrogen peroxide, decreasing activities of gaseous oxygen and water molecules. In addition, both MDA and LPO are considered to be the end products of lipid peroxidation and are markers of oxidative stress, leading to aging [32]. In this experiment, SOD, GSH-Px, and CAT activities were markedly elevated, while the contents of MDA and LPO were markedly depressed by administration of polysaccharides, indicating AMPS, especially at the dose of $400 \mathrm{mg} / \mathrm{kg} / \mathrm{d}$, has potential ability against D-gal-induced aging symptoms. The level of indicators in the blood can reflect the degree of damage of various tissues in the body, as well as the alleviating effect of AMPS on aging. ALT, CHE, TBIL, CREA, CK, AST, CHO, and GLU levels can be measured using a biochemical analyzer and were chosen as age-related indicators according to previous studies. The indicators above focused on the liver, kidney, and brain, with the aid of levels for lipids and glucose in serum as supplementary evidence for the first three tissues, thus guaranteeing the comprehensiveness and reliability of the data. ALT is released into the blood in large quantities when hepatocytes are necrotic in the acute phase, so it is an important indicator for the diagnosis of viral hepatitis [33]. The liver plays an important role in the metabolism of TBIL, including the three processes of uptake, binding, and excretion of unbound bilirubin in the blood by hepatocytes, and any obstacle in these processes can cause the accumulation of bilirubin in the blood [34]. When the corresponding liver cells are damaged, the permeability of the cell membrane increases and the AST in the cytoplasm is released into the blood, so the serum concentration 
of AST can be increased [35]. CREA is mainly excreted by glomerular filtration and its abnormal blood content indicates kidney damage in aging mice [36]. CK is mostly in the cytoplasm and mitochondria of myocardium, and is an important kinase that is directly related to intracellular energy movement, muscle contraction, and ATP regeneration, which are related to aging. Renal injury can be reflected to some extent with increasing content of CK [37]. Acetylcholinesterase has the strongest effect on the physiological concentration of acetyl choline (Ach) and higher specificity. The aging condition can be improved by restoring the content of acetylcholine in the cerebral cortex and reducing the activity of acetylcholinesterase [38]. Aging can lead to diabetes and other diseases. We explored the aging degree by detecting the glucose content in serum. In addition, $\mathrm{CHO}$ can be used as an indicator of blood lipids together with GLU to explore the efficacy of AMPS on D-gal-induced aging [39]. In the present study, each of the above eight indexes were decreased to a different degree compared with the MC group and some of them were even lower than that in the PC group at the dosage of $400 \mathrm{mg} / \mathrm{kg} / \mathrm{d}$ of AMPS, indicating that AMPS has commendable anti-aging activity in vivo. Regarding serum immunology, NGF can regulate the growth and development of peripheral and central neurons and maintain the survival of them. TNF- $\alpha$ can kill or inhibit tumor cells, enhance the phagocytosis of neutrophils, and induce the synthesis of proteins in the acute phase of hepatocytes. Bcl-2 acts on near or far target cells with the help of lymphocytes, which is a very important way to achieve immune effects and immune regulation [40-42]. In addition, the polysaccharide dose groups showed good immunological activity, which also indicated that AMPS had anti-aging activity in vivo. Because the indexes can be measured by biochemical analyzer, in order to get more accurate data in immunology, the NGF, TNF- $\alpha$, and Bcl-2 levels were measured by ELISA method mainly investigating brain injury, which could be used as a supplement to the CHE mentioned before. These three indicators just served as supplementary data for the value of the brain index measured, which was not obvious before. However, it could also reflect the extent of liver and kidney tissue damage caused by D-gal-induced aging to a certain extent. Compared with the model group, the histologic sections of liver, kidney, and brain under both doses of AMPS showed anesis in morphological features, indicating that the liver, kidney, and brain injuries were reduced. In other words, AMPS had a certain protective effect on them and was dose-dependent.

\section{Materials and Methods}

\subsection{Strains and Culture Conditions}

The fungus $P$. djamor strain was provided by Shandong Agricultural University and maintained by slants consisting of potato dextrose agar (PDA). The P. djamor in Petri dishes were inoculated into $1000 \mathrm{~mL}$ suction flasks containing PDA liquid medium $(500 \mathrm{~mL})$ and incubated on a rotary shaker at $130 \mathrm{rpm}$ for $7 \mathrm{~d}$ at $25^{\circ} \mathrm{C}$. Further, mycelia were acquired from fermentation cylinder by filtration.

\subsection{Preparation of AMPS}

The mycelia polysaccharides of (MPS) were prepared according to the method of Liu et al. [43], with slight modifications. The mycelia powder of P. djamor was mixed with proper distilled water for 4 $\mathrm{h}$ at $90^{\circ} \mathrm{C}$, then centrifuged at $3000 \mathrm{rpm}$ for $10 \mathrm{~min}$. The supernatant was concentrated, mixed three times with ethanol $(95 \%, v / v)$, and then kept at $4{ }^{\circ} \mathrm{C}$ overnight. After centrifugation (3000 rpm, $\left.10 \mathrm{~min}\right)$, the precipitate was collected and dried at $55^{\circ} \mathrm{C}$. The crude polysaccharides were deproteinized by employing the Sevage method [44] and lyophilized to obtain MPS.

The acetylated polysaccharides were obtained ulteriorly according to Jia et al. [45] with minor modifications. The reaction time, reaction temperature, and the amount of acetic anhydride were selected for the single-factor tests and response surface optimization experiment using the degree of substitution (DS) for response values.

The powered MPS (400 mg) was dissolved in distilled water ( $\mathrm{pH} 9.0$ ), adjusted by sodium hydroxide solution $(0.1 \mathrm{~mol} / \mathrm{L})$, and the acetylation procedure was processed according to the optimized conditions. The acetylated solution was neutralized with hydrochloric acid $(0.1 \mathrm{~mol} / \mathrm{L})$ after this 
reaction. The AMPS was obtained after centrifugation (3000 rpm, $10 \mathrm{~min}$ ), dialysis (Molecular weight cut off, $\left.\mathrm{MWCO}=3500,4^{\circ} \mathrm{C}, 3 \mathrm{~d}\right)$, concentration $\left(80^{\circ} \mathrm{C}\right)$, and lyophilization $(3 \mathrm{~d})$ (Beili, Beijing, China and SCIENTZ, Ningbo, China) and was considered to be AMPS.

\subsection{The DS Assay of AMPS}

\subsubsection{Standard Curve Plotting of Acetyl Content}

The DS of acetylation substitution was measured as previously reported [46], with a little adjustment. $\beta$-D-penta-acetyl glucopyranose $(0.6978 \mathrm{~g}, \mathrm{Mw}=390.34 \mathrm{u})$ was dissolved into $20 \mathrm{~mL}$ of ethyl alcohol adequately by $60{ }^{\circ} \mathrm{C}$ water-bath heating, then the solution was kept at a constant volume and shaken up in a $100 \mathrm{~mL}$ volumetric flask after cooling down to room temperature. Volumes of $2 \mathrm{~mL}, 4 \mathrm{~mL}, 6 \mathrm{~mL}, 8 \mathrm{~mL}, 10 \mathrm{~mL}$, and $12 \mathrm{~mL}$ were removed from the aforementioned $\beta$-D-penta-acetyl glucopyranose stock solution, respectively, and the $50 \mathrm{~mL}$ volumetric flask was used to keep the volume constant. The $\beta$-D-penta-acetyl glucopyranose standard solution was obtained after further dilution 10 times. The absorbance at $500 \mathrm{~nm}$ was acquired based on the series of concentration of acetyl.

\subsubsection{Calculation of AMPS Acetyl Substitution Degree}

A brown volumetric flask containing $10 \mathrm{~mL}$ sample solution $(1 \mathrm{mg} / \mathrm{mL}), 5 \mathrm{~mL}$ hydroxylamine hydrochloride $(0.1 \mathrm{~mol} / \mathrm{L})$, and $5 \mathrm{~mL}$ sodium hydroxide solution $(0.15 \mathrm{~mol} / \mathrm{L})$ was placed for $20 \mathrm{~min}$. The above solution was neutralized and ferric chloride $(0.37 \mathrm{~mol} / \mathrm{L}, 10 \mathrm{~mL})$ was added after $20 \mathrm{~min}$. The absorbance at $500 \mathrm{~nm}$ was measured after constant volume by deionized water. The acetylation substitution degree refers to the number of hydroxyl groups substituted by an acetyl group in average glucose loss per unit. The DS is expressed as

$$
\begin{gathered}
\mathrm{w}_{2}(\%)=\mathrm{W}_{2 /} \mathrm{W}_{1} \times 100, \\
\mathrm{DS}=162 \times \mathrm{w}_{2} /\left(4300-42 \times \mathrm{w}_{2}\right),
\end{gathered}
$$

where $\mathrm{w}_{2}$ is the mass fraction of the acetyl (\%), $\mathrm{W}_{1}$ is the quality of AMPS (mg), and $\mathrm{W}_{2}$ is the acetyl quality of AMPS (mg).

\subsection{FT-IR, HPLC, and NMR Analysis}

The AMPS (100 mg) was mixed with $\mathrm{KBr}$ powder (100-200 mg) and then pressed into pellets for infrared spectral analysis within a range from 4000 to $400 \mathrm{~cm}^{-1}$. The FT-IR spectrum was measured using a 6700 Nicolet Fourier transform-infrared spectrophotometer (Thermo Co., Madison, WI, USA).

The molecular weights were determined by HPLC, which was performed with an HPLC system (Aglient-1260 Infinity, Agilent Technologies, CA, USA) equipped with SB-802.5HQ, SB-804HQ column, an eight-angle laser light scatterometer (BI-MWA, Brookhaven instruments, Inc, USA), and a refractive index detector. The injection volume was $100 \mu \mathrm{L}$. The $\mathrm{NaCl}$ and $\mathrm{Na}_{2} \mathrm{HPO}_{4}$ aqueous solution was used as the mobile phase at a flow rate of $0.8 \mathrm{~mL} / \mathrm{min}$ and the column temperature was maintained at $25^{\circ} \mathrm{C}$. A series of standard dextrans were used to make the calibration curve. Molecular weight was analyzed by Agilent GPC software (Agilent 1260 Infinity Multi-Detector GPC/SEC System, A.02.01).

${ }^{1} \mathrm{H}$ and ${ }^{13} \mathrm{C}-\mathrm{NMR}$ measurements were conducted using a Bruker AV-300 spectrometer operating at $700 \mathrm{MHz}$ and $25^{\circ} \mathrm{C}$ and the sample was dissolved in deuterated water $\left(\mathrm{D}_{2} \mathrm{O}\right)$.

The monosaccharide composition of AMPS was determined by an HPLC system (Ultimate 3000, Agilent Technologies, CA, USA) equipped with Xtimate $C_{18}$ column $(4.6 \mathrm{~mm} \times 200 \mathrm{~mm} \times 5 \mathrm{um})$. The injection volume was $20 \mu \mathrm{L}$. The $0.05 \mathrm{~mol} / \mathrm{L}$ potassium dihydrogen phosphate-acetonitrile solution was used as the mobile phase at a flow rate of $1.0 \mathrm{~mL} / \mathrm{min}$, the column temperature was maintained at $30{ }^{\circ} \mathrm{C}$, and the test wavelength was $250 \mathrm{~nm}$. The mannose, ribose, rhamnose, glucuronic acid, galacturonic acid, glucosamine, glucose, galactose, galactose, xylose, arabinose, and fucose were critically weighed and diluted to $50 \mu \mathrm{g}$ mixed control solution in $1 \mathrm{~mL}$ each. After derivation 
of the sample solution and the mixed control solution, the monosaccharide composition of AMPS was explored.

\subsection{Antioxidant Activity In Vitro}

\subsubsection{Reducing Power Assay}

The reaction mixtures consisted of $1 \mathrm{~mL}$ AMPS (100-1400 mg/L), $2.5 \mathrm{~mL}$ phosphate buffer solution (pH 6.6, $0.2 \mathrm{~mol} / \mathrm{L})$, and $1 \mathrm{~mL}$ potassium ferricyanide $(1 \%, w / v)$. After incubating at $50{ }^{\circ} \mathrm{C}$ for $20 \mathrm{~min}$, $2 \mathrm{~mL}$ trichloroacetic acid $(10 \%, w / v)$ and $1.2 \mathrm{~mL}$ ferric trichloride $(1 \%, w / v)$ were added to the mixture. Thenm the absorbance was measured at $700 \mathrm{~nm}$ under the condition of zeroing by deionized water. The $\mathrm{EC}_{50}$ value $(\mathrm{mg} / \mathrm{L})$ was defined as the effective concentration of the sample at which reducing power reached half of the maximum.

\subsubsection{Scavenging DPPH Radical Assay}

The scavenging DPPH radical activity was determined according to Sun and Ho [47]. The reaction mixture contained DPPH ( $2 \mathrm{~mL}, 0.2 \mathrm{mmol} / \mathrm{L})$ and the sample $(2 \mathrm{~mL}, 100-1400 \mathrm{mg} / \mathrm{L})$. After shaking vigorously and incubating in the dark for $30 \mathrm{~min}$, the absorbance was measured at $517 \mathrm{~nm}$. A mixture of sample $(2 \mathrm{~mL})$ and absolute ethyl alcohol $(2 \mathrm{~mL})$ as blank group, deionized water $(2 \mathrm{~mL})$ and DPPH $(2 \mathrm{~mL})$ as a control group and the compound of deionized water $(2 \mathrm{~mL})$ and absolute ethyl alcohol $(2 \mathrm{~mL})$ was used for zero setting in this trial. The scavenging DPPH radical rate was expressed as

$$
\text { Scavenging ability }(\%)=[1-(\mathrm{Ai}-\mathrm{Aj}) / \mathrm{Ac}] \text {, }
$$

where $\mathrm{Ai}$ is the absorbance of the tested sample, $\mathrm{Aj}$ is the absorbance of the blank, and Ac is the absorbance of the control. The $\mathrm{IC}_{50}$ value $(\mathrm{mg} / \mathrm{L})$ was defined as the effective concentration of the sample at which DPPH radicals were inhibited by $50 \%$.

\subsubsection{Scavenging Hydroxyl Radical Assay}

The scavenging hydroxyl radical activity was determined according to Smirnoff and Cumbes [48], with some modifications. The $\mathrm{H}_{2} \mathrm{O}_{2}(1 \mathrm{~mL}, 8.8 \mathrm{mmol} / \mathrm{L})$ was added to the reaction system containing $\mathrm{FeSO}_{4}(1 \mathrm{~mL}, 9 \mathrm{mmol} / \mathrm{L})$, ortho-hydroxybenzoic acid $(1 \mathrm{~mL}, 9 \mathrm{mmol} / \mathrm{L})$, and the sample $(1 \mathrm{~mL}$, $100-1400 \mathrm{mg} / \mathrm{L}$ ) at $37^{\circ} \mathrm{C}$ for $30 \mathrm{~min}$. The absorbance was measured at $510 \mathrm{~nm}$ after centrifugation (1200 rpm, $6 \mathrm{~min}$ ). An equal amount of deionized water replaced the sample in this system as the control group and zeroed with deionized water. The scavenging hydroxyl radical activity was expressed as

$$
\text { Scavenging activity }(\%)=[1-(\mathrm{Aj}-\mathrm{Ai}) / \mathrm{Aj}],
$$

where $\mathrm{Ai}$ is the absorbance of the tested sample and $\mathrm{Aj}$ is the absorbance of the blank. The $\mathrm{IC}_{50}$ value $(\mathrm{mg} / \mathrm{L})$ was defined as the effective concentration of the sample at which hydroxyl radicals were inhibited by $50 \%$.

\subsubsection{Scavenging Superoxide Radical Assay}

The 11 test tubes were taken and numbered and $0.5 \mathrm{~mL}$ phosphate buffer solution was added (pH 7.8, $0.2 \mathrm{~mol} / \mathrm{L})$, along with $0.5 \mathrm{~mL}$ riboflavin $(10 \mathrm{mmol} / \mathrm{L}), 0.25 \mathrm{~mL}$ methionine $(13 \mathrm{mmol} / \mathrm{L})$, and $0.25 \mathrm{~mL}$ nitroblue tetrazolium $(15 \mathrm{mmol} / \mathrm{L})$, in order. Then, different concentrations of polysaccharide diluent $(100-1400 \mathrm{mg} / \mathrm{L})$ and deionized water were accreted into the 11 systems respectively $(1 \mathrm{~mL})$, reacting under $25^{\circ} \mathrm{C}$ for $20 \mathrm{~min}$ after blending. Absorbance values of the supernatant from the 11 systems at $560 \mathrm{~nm}$ were measured by using deionized water as a reference. The scavenging superoxide radical rate was evaluated according to the formula

$$
\text { Scavenging activity }(\%)=[1-(\mathrm{Aj}-\mathrm{Ai}) / \mathrm{Aj}] \text {, }
$$


where $\mathrm{Ai}$ is the absorbance of the tested sample and $\mathrm{Aj}$ is the absorbance of the blank. The $\mathrm{IC}_{50}$ value $(\mathrm{mg} / \mathrm{L})$ was defined as the effective concentration of the sample at which superoxide radicals were inhibited by $50 \%$.

\subsection{Oral Chronic Toxicity Test}

Twelve male Kunming strain mice were collected for the acute toxicity study. The mice were divided into two groups with six in each group and the mice were gavaged with AMPS at dosages of 300 and $900 \mathrm{mg} / \mathrm{kg} / \mathrm{d}$, respectively. The mice were observed continuously for toxic symptoms, mortality, and behavioral changes during the whole feeding period for 2 weeks.

\subsection{Anti-Aging Effect In Vivo}

\subsubsection{Animal Experiments}

Fifty Kunming mice $(20 \pm 2 \mathrm{~g})$ were purchased from Taibang Biological Products Ltd. Co. (Taian, China) and the animal experiments were approved through the institutional animal care and use committee of Shandong Agricultural University in accordance with the Animals (Scientific Procedures) Act of 1986 (amended 2013). The mice were acclimatized for 7 days under controlled conditions (20-25 ${ }^{\circ} \mathrm{C}$, lights on $12 \mathrm{~h}$ daily) with diet and water ad libitum. The mice of the control groups were randomly allocated into normal (NC), positive (PC), and model (MC) groups (ten mice in each group). The test group was further randomly and equally divided into the high dosage group (H-AMPS, $400 \mathrm{mg} / \mathrm{kg} / \mathrm{d}$ ) and low dosage group (L-AMPS, $200 \mathrm{mg} / \mathrm{kg} / \mathrm{d}$ ). The normal group was administered $0.2 \mathrm{~mL}$ normal saline and the other groups were administered $0.2 \mathrm{~mL} \mathrm{D}$-gal $(300 \mathrm{mg} / \mathrm{kg} / \mathrm{d})$ through intraperitoneal injection. After $8 \mathrm{~h}$, the normal and model groups were treated with $0.2 \mathrm{~mL}$ normal saline, the PC group was treated with $0.2 \mathrm{~mL}$ ascorbic acid ( $\mathrm{Vc}_{\mathrm{c}}, 300 \mathrm{mg} / \mathrm{kg} / \mathrm{d}$ ) through gastric gavage, and the test groups were gavaged with $0.2 \mathrm{~mL}$ of different concentration polysaccharides. After six weeks, the mice were fasted overnight and sacrificed through exsanguination under diethyl ether anesthesia.

\subsubsection{Biochemical Analysis}

The livers, kidneys, and brains were rapidly removed, weighed, and immediately homogenized $(1: 9, w / v)$ in phosphate buffer solution $\left(0.2 \mathrm{M}, \mathrm{pH} 7.4,4^{\circ} \mathrm{C}\right)$. After centrifugation $\left(5000 \mathrm{rpm}, 4^{\circ} \mathrm{C}\right)$ for $20 \mathrm{~min}$, the supernatants were collected for further biochemical analysis. The activities of GSH-Px, SOD, and CAT, as well as the contents of MDA and LPO in the liver, kidney, and brain, were assayed using commercially available diagnostic kits (Nanjing Jiancheng Bioengineering Institute, Nanjing, China).

The blood samples obtained from the retrobulbar veins were centrifuged at $14,000 \mathrm{rpm}$ at $4{ }^{\circ} \mathrm{C}$ for 10 min to gain the serum. The activities of ALT, CHE, CK, and AST and the levels of TBIL, CREA, CHO, and GLU were analyzed using an automatic biochemical analyzer (ACE, USA). Moreover, the NGF, $\mathrm{TNF}-\alpha$, and Bcl-2 levels in the serum were evaluated by commercial kits, according to independent instructions of the ELISA method.

\subsubsection{Histopathological Analysis}

According to the method of Zhu et al. [49], the livers, kidneys, and brains were removed and rapidly immersed into formalin solution $(10 \%, v / v, \mathrm{pH} 7.4)$ with the purpose of buffering and fixation for 7 days. Then the tissues of each group were divided into small tea bags with labels. After three days of running water flushing, the tissues were rapidly put into ethanol (50\%), further dehydrated by gradient ethanol solution, and then administered transparent processing with xylene. After immersion in paraffin ( 3 times successively for $2 \mathrm{~h}$ each time) and embedding, tissues were cut into $5 \mu \mathrm{m}$ slices. The glass slides were accompanied by paraffin section into $60^{\circ} \mathrm{C}$ oven for 2 days. Xylene and gradient ethanol were used for deparaffinating and hydration, respectively. The samples were observed under the microscope and photographed at $400 \times$ magnification to evaluate the morphological changes after 
hematoxylin-eosin ( $\mathrm{H}$ and $\mathrm{E}$ ) staining, distilled water washing, gradient ethanol, and xylene treatment, in sequence.

\subsection{Statistical Analysis}

All experiments were performed in triplicate and the results are presented as the means \pm standard deviations (SD). The results were analyzed using one-way analysis of variance (ANOVA) with the IBM SPSS Statistical software package program. $p<0.05$ was considered statistically significant.

\section{Conclusions}

This experiment proved that the AMPS from P. djamor had good antioxidant activity in vitro, anti-aging activity in vivo, and protective effects on the liver, kidney, and brain. It was verified that acetylation was a suitable modification method for the mycelia polysaccharides from P. djamor, indicating that AMPS can be used as a functional food and nutritional medicine for the treatment of aging and age-related diseases.

Supplementary Materials: The following are available online, Supplementary Files S1.

Author Contributions: H.L., J.Z. and L.J. designed the research. H.L., H.Z., and Z.G. performed the research and analyzed the data. H.L., X.S., and W.W. prepared the figures and tables. H.L. wrote the manuscript. F.Y., Y.F., and Y.Z. contributed to the improvements of the English language. L.J. and S.Z. provided the funds for the experiments. All authors were involved in checking the paper and contributed to the preparation of the final manuscript. All authors read and approved the final manuscript.

Funding: This work was supported by grants from Mushroom Technology System of Shandong Province (SDAIT-07-05).

Conflicts of Interest: The authors declare that they have no competing interests.

Compliance with Ethical Standards: The experiments were performed as approved by the Institutional Animal Care and Use Committee of Shandong Agricultural University, and in accordance with the Animals (Scientific Procedures) Act 1986 (amended 2013).

\section{Abbreviations}

Acetylated mycelia polysaccharides: AMPS; aspartate aminotransferase: ALT; ascorbic acid: Vc; alanine transaminase: AST; B-lymphoma factor: Bcl-2; catalase: CAT; cholinesterase: CHE; creatinine: CREA; creatine kinase: CK; degree of substitution: DS; D-galactose: D-gal; glucose: GLU; glutathione peroxidase: GSH-Px; high dosage AMPS: H-AMPS; lipid peroxide: LPO; low dosage AMPS: L-AMPS; malondialdehyde: MDA; mean grain size: Mz; model control group: MC group; nerve growth factor: NGF; normal control group: NC group; number-average molecular weight: Mn; positive control group: PC group; potato dextrose agar: PDA; superoxide dismutase: SOD; total bilirubin: TBIL; total cholesterol: $\mathrm{CHO}$; tumor necrosis factor: TNF- $\alpha$; weight-average molecular weight: Mw.

\section{References}

1. Govindan, S.; Johnson, E.E.R.; Christopher, J.; Shanmugam, J.; Thirumalairaj, V.; Gopalan, J. Antioxidant and anti-aging activities of polysaccharides from Calocybe indica var. APK2. Exp. Toxicol. Pathol. 2016, 68, 329-334. [CrossRef] [PubMed]

2. Lin, L.; Cui, F.; Zhang, J.; Gao, X.; Zhou, M.; Xu, N.; Zhao, H.; Liu, M.; Zhang, C.; Jia, L. Antioxidative and renoprotective effects of residue polysaccharides from Flammulina velutipes. Carbohydr. Polym. 2016, 146, 388-395. [CrossRef] [PubMed]

3. Huangfu, J.; Liu, J.; Sun, Z.; Wang, M.; Jiang, Y.; Chen, Z.Y.; Chen, F. Anti-aging effects of astaxanthin-rich alga haematococcus pluvialis on fruit flies under oxidative stress. Food Chem. 2013, 61, 7800-7804. [CrossRef] [PubMed]

4. Mu, X.; Zhang, Y.; Li, J.; Xia, J.; Chen, X.; Jing, P.; Song, X.; Wang, L.; Wang, Y. Angelica sinensis polysaccharide prevents hematopoietic stem cells senescence in D-galactose-induced aging mouse model. Stem Cells Int. 2017, 3, 3508907. [CrossRef] [PubMed] 
5. $\quad$ Ding, Q.Y.; Yang, D.; Zhang, W.N.; Lu, Y.M.; Zhang, M.Z.; Wang, L.M.; Li, X.H.; Zhou, L.Y.; Wu, Q.X.; Pan, W.J.; et al. Antioxidant and anti-aging activities of the polysaccharide TLH-3 from Tricholoma lobayense. Int. J. Biol. Macromol. 2016, 85, 133-140. [CrossRef] [PubMed]

6. Zhang, Z.F.; Lv, G.Y.; He, W.Q.; Shi, L.G.; Pan, H.J.; Fan, L.F. Effects of extraction methods on the antioxidant activities of polysaccharides obtained from Flammulina velutipes. Carbohydr. Polym. 2013, 98, 1524-1531. [CrossRef] [PubMed]

7. Wasser, S. Medicinal mushrooms as a source of antitumor and immunomodulating polysaccharides. Appl. Microbiol. Biotechnol. 2002, 60, 258-274. [PubMed]

8. Jin, M.L.; Zhao, K.; Huang, Q.S.; Xu, C.L.; Shang, P. Isolation, structure and bioactivities of the polysaccharides from Angelica sinensis (Oliv.) Diels: Areview. Carbohydr. Polym. 2012, 89, 713-722. [CrossRef] [PubMed]

9. Zhao, H.J.; Li, S.S.; Zhang, J.J.; Che, G.; Zhou, M.; Liu, M.; Zhang, C.; Xu, N.; Lin, L.; Liu, Y.; et al. The antihyperlipidemic activities of enzymatic and acidic intracellular polysaccharides by Termitomyces albuminosus. Carbohydr. Polym. 2016, 151, 1227-1234. [CrossRef] [PubMed]

10. Su, J.; Jiang, L.L.; Wu, J.N.; Liu, Z.Y.; Wu, Y.P. Anti-tumor and anti-virus activity of polysaccharides extracted from Sipunculus nudus (SNP) on Hepg 2.2.15. Int. J. Biol. Macromol. 2016, 87, 597-602. [CrossRef] [PubMed]

11. Zhang, J.J.; Liu, M.; Yang, Y.H.; Lin, L.; Xu, N.; Zhao, H.J.; Jia, L. Purification, characterization and hepatoprotective activities of mycelia zinc polysaccharides by Pleurotus djamor. Carbohydr. Polym. 2016, 136, 588-597. [CrossRef] [PubMed]

12. Chen, Y.; Zhang, H.; Wang, Y.; Nie, S.; Li, C.; Xie, M. Acetylation and carboxymethylation of the polysaccharide from Ganoderma atrum and their antioxidant and immunomodulating activities. Food Chem. 2014, 156, 279-288. [CrossRef] [PubMed]

13. Liang, Z.Y.; Miao, C.Y.; Zhang, Y.S. Study on the effect of chemical modification on the antitumor activity of polysaccharides from Acrodia obliquus. Chin. J. Pharm. 1996, 10, 37-39.

14. Song, Y.; Yang, Y.; Zhang, Y.; Duan, L.; Zhou, C.; Ni, Y.; Liao, X.; Li, Q.; Hu, X. Effect of acetylation on antioxidant and cytoprotective activity of polysaccharides isolated from pumpkin (Cucurbita pepo, lady godiva). Carbohydr. Polym. 2013, 98, 686-691. [CrossRef] [PubMed]

15. Peng, X.B.; Li, Q.; Ou, L.N.; Jiang, L.F.; Zeng, K. GC-MS, FT-IR analysis of black fungus polysaccharides and its inhibition against skin aging in mice. Int. J. Biol. Macromol. 2010, 47, 304-307. [CrossRef] [PubMed]

16. Takeda, M.; Kondo, K.; Sanda, S.; Kan, D.; Borges, I.K.; Suzuki, I.; Katahira, M. Enzymatic degradation of $\beta-1$, 4-linked N-acetylglucosaminoglucan prepared from Thiothrix nivea. Int. J. Biol. Macromol. 2017, 109, 323-328. [CrossRef] [PubMed]

17. Pang, F.; Liu, C.Y.; Chen, K.S.; Wang, H. Recent advances in the modification of polysaccharides by acetylation. Aug. Fir. Land Reclam. Univ. 2017, 29, 42-47.

18. Song, X.; Shen, Q.; Liu, M.; Zhang, C.; Zhang, L.; Ren, Z.; Wang, W.; Dong, Y.; Wang, X.; Zhang, J.; et al. Antioxidant and hepatoprotective effects of intracellular mycelium polysaccharides from Pleurotus geesteranus, against alcoholic liver diseases. Int. J. Biol. Macromol. 2018, 114, 979-988. [CrossRef]

19. Chang, Y.F.; Gong, W.X.; Zheng, Y.H.; Li, J.W.; Zhou, Y.Z.; Qin, X.M.; Du, G.H. Urinary metabolomics study of the effects of Scutellaria baicalensis Georgi ethanol extract on D-galactose-induced rats. Acta Pharm. Sin. 2016, 51, 86-92.

20. Mo, R.; Wei, Z.M.; Yang, Y.S. Research progress in anti-aging mechanism. Med. J. Chin. PLA 2017, 42, 743-748.

21. Fan, Y.L.; Xia, J.Y.; Jia, D.Y. Protective effect of Angelica sinensis polysaccharides on subacute renal damages induced by D-galactose in mice and its mechanism. China J. Chin. Mater. Med. 2015, 40, 4229.

22. Sies, H. Oxidative stress: A concept in redox biology and medicine. Redox Biol. 2015, 4, 180-183. [CrossRef] [PubMed]

23. Yan, L.J. Positive oxidative stress in aging and aging-related disease tolerance. Redox Biol. 2014, 2, 165-169. [CrossRef] [PubMed]

24. Zhang, C.; Gao, Z.; Hu, C.; Zhang, J.; Sun, X.; Rong, C.; Jia, L. Antioxidant, antibacterial and anti-aging activities of intracellular zinc polysaccharides from Grifola frondosa SH-05. Int. J. Biol. Macromol. 2017, 95, 778-787. [CrossRef] [PubMed]

25. Yuan, H.; Zhang, W.; Li, X.; Lü, X.; Li, N.; Gao, X.; Song, J. Preparation and in vitro antioxidant activity of kappa-carrageenan oligosaccharides and their oversulfated, acetylated, and phosphorylated derivatives. Carbohyd. Res. 2005, 340, 685-692. [CrossRef] [PubMed] 
26. Tao, Y.Z.; Zhang, Y.Y.; Zhang, L.N. Chemical modification and antitumor activities of two polysaccharide protein complexes from Pleurotus tuber-regium. Int. J. Biol. Macromol. 2009, 45, 109-115. [CrossRef] [PubMed]

27. Ma, L.; Chen, H.; Zhang, Y.; Zhang, N.; Fu, L. Chemical modification and antioxidant activities of polysaccharide from mushroom Inonotus obliquus. Carbohydr. Polym. 2012, 89, 371-378. [CrossRef]

28. Zeng, W.C.; Zhang, Z.; Gao, H.; Jia, L.R.; Chen, W.Y. Characterization of antioxidant polysaccharides from Auricularia auricular using microwave-assisted extraction. Carbohydr. Polym. 2012, 89, 694-700. [CrossRef]

29. Lin, R.S.; Liu, H.H.; Wu, S.Q.; Pang, L.F.; Jia, M.S.; Fan, K.M.; Jia, S.H.; Jia, L. Production and in vitro antioxidant activity of exopolysaccharide by a mutant, Cordyceps militaris SU5-08. Int. J. Biol. Macromol. 2012, 51, 153-157. [CrossRef]

30. Finkel, T.; Holbrook, N.J. Oxidants, oxidative stress and the biology of aging. Nature 2000, 408, $239-247$. [CrossRef]

31. Kumar, A.; Prakash, A.S. Dogra Naringin alleviates cognitive impairment, mitochondrial dysfunction and oxidative stress induced by D-galactose in mice. Food Chem. Toxicol. 2010, 48, 626-632. [CrossRef] [PubMed]

32. Li, S.; Li, J.; Zhang, J.; Wang, W.; Wang, X.; Jing, H.; Ren, Z.; Gao, Z.; Song, X.; Gong, Z.; et al. The Antioxidative, Antiaging, and hepatoprotective effects of alkali-extractable polysaccharides by Agaricus bisporus. Evid. Based Complement. Altern. 2017, 2017. [CrossRef] [PubMed]

33. Bovera, F.; Moniello, G.; De Riu, N.; Di Meo, C.; Pinna, W.; Nizza, A. Effect of diet on the metabolic profile of ostriches (Struthio camelusvar.domesticus). Trop. Anim. Health Prod. 2007, 39, 265-270. [CrossRef] [PubMed]

34. Huang, S.Z.; Luo, Y.J.; Wang, L.; Cai, K.Y. Effect of ginkgo biloba extract on livers in aged rats. World J. Gastroenterol. 2005, 11, 132-135. [CrossRef] [PubMed]

35. Connolly, M.K.; Bedrosian, A.S.; Malhotra, A.; Henning, J.R.; Ibrahim, J.; Vera, V.; Cieza-Rubio, N.E.; Hassan, B.U.; Pachter, H.L.; Cohen, S.; et al. In Hepatic fibrosis, liver sinusoidal endothelial cells acquire enhanced immunogenicity. J. Immunol. 2010, 185, 2200-2208. [CrossRef] [PubMed]

36. Liu, X.; Liu, R.; Dai, Z.; Wu, H.; Lin, M.; Tian, F.; Gao, Z.; Zhao, X.; Sun, Y.; Pu, X. Effect of Shenfu injection on lipopolysaccharide (LPS)-indu-ced septic shock in rabbits. J. Ethnopharmacol. 2019, 234, 36-43. [CrossRef] [PubMed]

37. Spada, T.C.; Silva, J.M.; Francisco, L.S.; Marçal, L.J.; Antonangelo, L.; Zanetta, D.M.; Yu, L.; Burdmann, E.A. High intensity resist-ance training causes muscle damage and increases biomarkers of acute ki-dney injury in healthy individuals. PLoS ONE 2018, 13, e0205791. [CrossRef] [PubMed]

38. Rui, X.; Wenfang, L.; Jing, C.; Meng, C.; Chengcheng, D.; Jiqu, X.; Shuang, R. Neuroprotective effects of phytosterol esters against high cholesterol-induced cognitive deficits in aged rat. Food Funct. 2017, 8, 1323-1332. [CrossRef] [PubMed]

39. Ibrahim, S.E.M.; Kosba, A.A. Royal jelly supplementation reduces skeletal muscle lipotoxicity and insulin resistance in aged obese rats. Pathophysiology 2018, 25, 307-315. [CrossRef]

40. Zhang, W.; Zhang, Y.; Yao, L.; Djang, A.H. Effects of Oncolyn on ATPase activity and expression of nerve growth factor in brain tissue of aging mice. Health Res. 2007, 36, 164-166.

41. Li, G.; Wang, H.W.; Si, H.L.; Yang, Q.; Jiang, X.F. Action and adjustment of Xinzhi Bimin capsule on the content of IL-13 in blood serum and expression of STAT6 in nasal mucosa of rat model with allergic rhinitis. Chin. J. Immunol. 2010, 26, 901-909.

42. Pan, C.Y.; Yang, S.S.; Fu, H.L.; Miu, M.Y.; Jiao, B.H. Inhibitory effect of high expression of B-cell lymphoma factor Bcl-6 on apoptosis of rat hepatocytes. Second Mil. Med. Univ. Acad. J. 2013, 32, 349-354. [CrossRef]

43. Liu, M.; Jing, H.; Zhang, J.; Che, G.; Zhou, M.; Gao, Z.; Li, S.; Ren, Z.; Hao, L.; Liu, Y.; et al. Optimization of mycelia selenium polysaccharide extraction from Agrocybe cylindracea SL-02 and assessment of their antioxidant and anti-ageing activities. PLoS ONE 2016, 11, e0160799. [CrossRef] [PubMed]

44. Miao, S.S.; Mao, X.H.; Pei, R.; Miao, S.P.; Xiang, C.; Lv, Y.J.; Yang, X.G.; Sun, J.; Jia, S.S.; Liu, Y.P. Antitumor activity of polysaccharides from Lepista sordida against laryngocarcinoma in vitro and in vivo. Int. J. Biol. Macromol. 2013, 60, 235-240. [CrossRef] [PubMed]

45. Jia, H.Q.; Liu, W.; Yan, J.; Liang, L.; Zheng, R.F.; Wang, X.J.; Gou, X.J.; He, G. Isolation, purification, acetylation modification and antioxidant activity of polysaccharides from Pleurotus erinatus. Food Ind. Technol. 2018, 39, 39-44.

46. Yang, C.Y.; Yang, C.L.; Liu, H.L.; Jing, Z.G.; Xu, X.X.; Wang, T.H. Study on the preparation and antioxidant activity of polysaccharides from acetylated Auricularia Japonica. Sci. Technol. Food Ind. 2015, 36, 105-115. 
47. Sunk, T.; Ho, C.T. Antioxidant activities of buckwheat extracts. Food Chem. 2005, 90, 743-749.

48. Smirnoff, N.; Cumbes, Q.J. Hydroxyl radical scavenging activity of compatible solutes. Phytochemistry 1989, 28, 1057-1060. [CrossRef]

49. Zhu, X.Y.; Ma, P.S.; Wu, W.; Zhou, R.; Hao, Y.J.; Niu, Y.; Sun, T.; Li, Y.X.; Yu, J.Q. Neuroprotective actions of taurine on hypoxic-ischemic brain damage in neonatal rats. Brain Res. Bull. 2016, 124, 295-305. [CrossRef]

Sample Availability: Samples of the compounds are available from the authors.

(C) 2019 by the authors. Licensee MDPI, Basel, Switzerland. This article is an open access article distributed under the terms and conditions of the Creative Commons Attribution (CC BY) license (http://creativecommons.org/licenses/by/4.0/). 